\title{
APRESENTAÇÃO
}

\section{O BRASIL E A DIÁSPORA HAITIANA}

\author{
Ana Elisa Bersani ${ }^{1}$ \\ Handerson Joseph ${ }^{2}$
}

Desde o século XIX, os haitianos circulam entre diferentes espaços nacionais e transnacionais, notadamente no Caribe, na América do Norte, na América do Sul e na Europa, tradicionalmente em países que constituem a diáspora haitiana como os Estados Unidos, o Canadá, a França, a República Dominica e Cuba. Isto é evidência de que a mobilidade é um fenômeno antigo e estrutural no universo haitiano. Entretanto, a partir de 2010, após o terremoto no Haiti, teve início "um quarto grande fluxo da mobilidade internacional haitiana" (JOSEPH, 2015a, 2017a e 2017b) em direção ao Equador, ao Peru, ao Chile, à Argentina, e sobretudo, ao Brasil. ${ }^{3}$

\footnotetext{
1 Bacharel em Ciências Sociais pela Universidade de São Paulo (2010) e mestra em Antropologia Social pela Universidade Estadual de Campinas (2015). Atualmente é doutoranda no Programa de Pós-Graduação em Antropologia Social da Universidade Estadual de Campinas, onde desenvolve pesquisa com especial interesse nas áreas de Antropologia Médica e da Saúde, Antropologia do Desenvolvimento e da Ajuda Humanitária, com ênfase em contextos de crise e pós-desastre. E-mail: anabersani@hotmail.com

2 Doutor em Antropologia Social pelo Museu Nacional/UFRJ (2015), com doutorado Sanduíche pela École Normale Supérieure (ENS) e pela École des Hautes Études en Sciences Sociales (EHESS) em Paris. Atualmente é Professor do Programa de Pós-Graduação em Estudos de Fronteira (PPGEF) da Universidade Federal do Amapá e do Programa de PósGraduação em Antropologia pela Université d’État d’Haïti, atuando principalmente nos seguintes temas: Diáspora; Mobilidade; Migrações transfronteiriças; Relações Étnicorraciais; Religiões afro-brasileiras e caribenhas; Pós-colonialismo. E-mail: handersonj_82@yahoo.es ${ }^{3}$ Estima-se que 20 mil haitianos estejam residindo atualmente no Equador (Dirección Nacional de Migración), 10 mil no Peru (Superintendencia Nacional de Migraciones), 50 mil no Chile
} 
Mais do que um espaço de chegada ou saída, o Brasil foi se tornando um lugar privilegiado e estratégico nas dinâmicas das mais recentes configurações migratórias haitianas para os referidos países da América do Sul, bem como uma etapa em direção ao México e aos Estados Unidos. Em um período de sete anos (de 2010 a 2017), o Brasil se transformou no sexto país em importância no espaço da mobilidade internacional haitiana, atrás apenas dos Estados Unidos, do Canadá, da França, da República Dominicana e de Cuba (JOSEPH, 2017d). Atualmente, no Brasil, há o dobro de haitianos em relação à Guiana Francesa, no qual tal presença se faz desde a década de 1960 (JOSEPH, 2015a e 2016).

Apesar das relações entre Haiti e Brasil remontarem à década de 1940, particularmente no campo diplomático, foi a partir de 2004 que elas se intensificaram. No referido ano, o Haiti se tornou espaço de atuação de várias instituições brasileiras, como, por exemplo, as tropas militares da Missão das Nações Unidas para a Estabilização do Haiti (MINUSTAH), além de outras Organizações Não-Governamentais (ONGs) e religiosas brasileiras já presentes no país.

Nos últimos oito anos, o espaço da mobilidade supranacional e transfronteiriço Haiti-Brasil se constituiu na esteira da construção da ideia do Brasil como "terra de oportunidades", na qual é possível chache lavi miyò (tentar uma vida melhor) (BERSANI, 2016). Tal visão é difundida no mundo social haitiano, tanto no Haiti quanto no exterior, em razão do papel político e econômico de destaque que o Brasil passou a ocupar no cenário mundial. A postura pública de abertura e hospitalidade adotada internacionalmente pelo governo brasileiro e a expectativa da existência de uma demanda de mão de obra para o trabalho nas obras da Copa do Mundo de 2014 e dos Jogos Olímpicos de 2016, entre outros fatores, contribuíram para que o Brasil, além de ser um "corredor de passagem", uma etapa, também se tornasse um novo polo internacional da diáspora haitiana.

(Departamento de Extranjería y Migraciones), 7 mil na Argentina (Dirección Nacional de Migraciones), e 80 mil no Brasil (Ministério de Justiça). Tais dados devem ser, no entanto, problematizados, uma vez que mensurar um mundo em movimento e que, em grande medida, transita por caminhos irregulares é uma tarefa quase impossível.

Temáticas, Campinas, 25, (49/50): 09-16, fev./dez. 2017 
Nesse sentido, tendo como pano de fundo a situação dos migrantes e refugiados no contexto global atual e a ênfase nas dinâmicas migratórias Sul-Sul, este Dossiê nos convida a refletir e a analisar a problemática migratória no Brasil de forma ímpar, revelando os percalços nacionais na acolhida de um fluxo crescente de solicitantes de refúgio, ao mesmo tempo em que, de um ponto de vista mais macro, chama atenção para tensões que rondam os deslocamentos contemporâneos de modo geral.

Desta forma, o objetivo do Dossiê intitulado Dinâmicas migratórias baitianas no Brasil: desafios e contribuicões é reunir trabalhos que discutem, através de uma perspectiva inter e transdisciplinar, as múltiplas relações estabelecidas em torno dos circuitos Haiti-Brasil e da presença dos haitianos no Brasil. Trata-se, portanto, de contribuir para a produção de conhecimento sobre as dinâmicas que envolvem os processos migratórios através das trajetórias e experiências vividas pelos haitianos nesse espaço, suas atuações e contribuições em áreas diversas como saúde, trabalho, religião, educação etc., considerando o impacto dessa presença na transformação das relações sociais, nas paisagens locais e nas trajetórias dos próprios haitianos.

Mais do que isso, a reflexão proposta por este Dossiê busca escapar da linguagem da "crise" e da "emergência" mobilizada pela imprensa nacional e internacional, ora através do viés humanitário, ora da securitização, para trazer novos elementos na composição de um quadro de pesquisas complexo e desafiante do ponto de vista teórico e metodológico.

\section{ESTRUTURA DO DOSSIÊ}

Abrimos este número com o artigo de Kassoum Dieme, que aborda o tema das migrações haitianas ao longo da história, situando o Brasil enquanto destino recente da diáspora haitiana. $\mathrm{O}$ autor também reflete sobre a política de acolhimento institucional brasileira e as condições de existência e permanência dessa população no país nos últimos oito anos.

Em seguida, o texto de Stéphane Granger amplia a discussão a partir da análise das novas dinâmicas migratórias na Guiana Francesa. Ao olhar 
para as mudanças nos fluxos migratórios tradicionais e para a novidade que o caminho para o Brasil representa, o autor discute o impacto desse fenômeno nas estratégias de permanência no território franco-guianense e lança luz sobre as vicissitudes desse trânsito.

É justamente sobre as implicações pragmáticas desse recente fluxo que Isis do Mar Marques Martins nos convida à reflexão. Baseando-se em conceitos contemporâneos da geografia, como capilaridade e territóriorede, a autora se propõe a pensar os atravessamentos sociais e políticos imbricados no espaço e no tempo da permanência de haitianos no Brasil.

$\mathrm{O}$ artigo de Claudete Gomes Soares e Neuri José Andreola contribui com uma importante discussão acerca dos significados atribuídos à presença haitiana no oeste catarinense, estado localizado no sul do Brasil. Os autores exploram como a ideia de branquitude, associada à identidade europeia, é acionada nas relações entre os moradores locais e os migrantes haitianos, fundamentando uma relação de poder baseada em uma suposta superioridade racial, nacional e de origem.

Ainda no bojo das representações sociais sobre os migrantes haitianos, o artigo de Daniel Granada e Priscila Pavan Detoni propõe uma investigação acerca dos serviços de saúde a partir dos corpos dos migrantes e das patologias associadas a eles. Os autores partem de entrevistas realizadas, entre 2014 e 2016, com agentes comunitários de saúde em um município de médio porte no Sul do Brasil para discutir os possíveis efeitos de tais representações no acesso aos serviços de saúde.

A partir da perspectiva da sociologia do trabalho, a autora Letícia Helena Mamed aborda o percurso e a experiência de migrantes haitianas que têm suas trajetórias laborais conectadas à cadeia agroindustrial da carne no Sul do Brasil. Ao refletir sobre os significados do projeto migratório de migrantes mulheres negras no Brasil, a autora realiza uma análise cruzada entre trabalho e gênero. O itinerário dessas mulheres é apresentado através de uma etnografia multisituada, de modo a problematizar o lugar de exploração e precariedade ocupado por elas em um mercado de trabalho desigual e segregado.

A especificidade da condição feminina no contexto migratório também é objeto da reflexão trazida por Rafaela Gava Etechebere, em 
um artigo que discute os acontecimentos que marcam as vidas e corpos de haitianas que se estabeleceram em Santa Barbara d'Oeste, no interior do estado de São Paulo. As experiências ligadas à precarização do trabalho e ao racismo são abordadas aqui, a partir do exame das narrativas das interlocutoras, no esforço de refletir sobre as possibilidades do exercício da maternidade, através das ações de "prover" e de "cuidar" na vivência cotidiana da mobilidade.

Em seguida, por meio de um outro cruzamento analítico, Frantz Rousseau Déus investiga em seu artigo o papel desempenhado pela religião no suporte aos migrantes haitianos que se estabelecem no Brasil. O autor desenvolve pesquisa junto aos seguidores da religião Testemunhas de Jeová na cidade de Campinas, interior de São Paulo, e ressalta a importância da construção dos laços afetivos para a integração social dos haitianos na sociedade brasileira.

Os últimos dois artigos propõem uma investigação acerca da presença dos haitianos no ensino superior brasileiro. Fritznel Alphonse e José Rivair Macedo analisam o programa Pró-Haiti implementado em universidades públicas como a UNICAMP, UFSC, UFSCAR e UFRGS, entre 2011 e 2016. Ao retraçar o histórico do programa, de um ponto de vista bastante crítico, os autores também problematizam as relações bilaterais entre Brasil e Haiti, apontando suas intensões e limites. O texto apresentado tem o mérito de olhar para os resultados do programa levando em conta a forma como ele foi executado na prática e a experiência dos próprios sujeitos "beneficiados" por ele. Em um outro artigo, Wendy Ledix também reflete sobre a inserção e participação dos haitianos nas universidades brasileiras, a partir das experiências da Universidade Federal da Fronteira Sul (UFFS), em Chapecó, e da Universidade Federal da Integração Latino-Americana (UNILA).

Finalmente, o ensaio fotográfico "A chegada", de Letícia Helena Mamed, fecha esse número com um registro precioso da chegada de migrantes haitianos no Acre, entre 2011 e 2015, na região da Tríplice Fronteira Brasil-Bolívia-Peru, e da acomodação dessa população em abrigos e acampamentos improvisados em diferentes cidades do estado. 
O dossiê Dinâmicas migratórias haitianas no Brasil: desafios e contribuições traz para a revista Temáticas uma reflexão acerca dos desafios teóricos e metodológicos que a pesquisa com migrantes haitianos no universo brasileiro evidencia, no que tange às questões raciais, educacionais, religiosas, bem como de trabalho, gênero, saúde, entre outras. Como organizadores nossa intenção foi reunir contribuições a partir de diferentes perspectivas epistêmicas e abordagens metodológicas, de autores que têm como lugar de partida universos diversos, mas que igualmente se debruçam sobre as dinâmicas migratórias haitianas.

A proposta deste Dossiê é, portanto, contribuir para as Ciências Sociais através de diálogos pluridisciplinares, suscitando debates sobre as diversas possibilidades e caminhos para a reflexão em torno do tema em questão. Uma das singularidades deste número é o fato de contar com a contribuição de pesquisadores haitianos, como Frantz Rousseau Déus, Fritznel Alphonse e Wendy Ledix, além de Handerson Joseph como organizador, que vivenciam a experiência migratória e desenvolvem pesquisas no contexto brasileiro, desempenhando um importante papel enquanto agentes da produção de conhecimento através do circuito HaitiBrasil.

\section{REFERÊNCIAS BIBLIOGRÁFICAS}

BERSANI, Ana Elisa. "Chache lavi Deyò: uma reflexão sobre a categoria refúgio a partir da diaspora haitiana no Brasil". Cadernos de Campo, São Paulo, 25, 2016. Disponível em: https://www.revistas.usp.br/ cadernosdecampo/article/download/129282/134127

JOSEPH, Handerson. Diaspora. As dinâmicas da mobilidade baitiana no Brasil, no Suriname e na Guiana Francesa. Tese de (Doutorado em Antropologia Social) - PPGAS, Museu Nacional/Universidade Federal do Rio de Janeiro, Rio de Janeiro, 2015a. Disponível em: https:// www.academia.edu/15267521/Tese_de_doutorado_Diaspora._ As_din\%C3\%A2micas_da_mobilidade_haitiana_no_Brasil_no_ Suriname_e_na_Guiana_Francesa_?auto=download 
"Diaspora. Sentidos sociais e mobilidades haitianas". Horizontes Antropológicos, 21, 2015b. Disponível em: http://dx.doi.org/10.1590/ S0104-71832015000100003http://dx.doi.org/10.1590/S010471832015000100003

- "Criando associações: migrantes haitianos na Guiana Francesa e no Brasil". Caderno de Debates, Refúgio, Migrações e Cidadania, 11, 2016. Disponível em: http://www.migrante.org.br/components/ com_booklibrary/ebooks/Caderno $\% 20$ de $\% 20$ Debates $\% 2011 \% 20$ ano $\% 202016 \% 20$ FINAL.pdf

"Diaspora, circulation et mobilité: les jeunes Haïtiens au Brésil". In: Louis Herns Marcelin; Toni Cela; Dorvil Henri (orgs.), Les jeunes Haïtiens dans les Amériques // Haitian youth in the Americas. Collection Problèmes sociaux et interventions sociales. Montréal: Presses de l'Université du Québec (PUQ). 2017a. Disponível em: https:// www.puq.ca/catalogue/themes/les-jeunes-haitiens-dans-lesameriques-3245.html

"A historicidade da (e)migração internacional haitiana. O Brasil como novo espaço migratório". Periplos, GT Clacso - Migración SurSur, 1, 2017b. Disponível em: http://periodicos.unb.br/index.php/ obmigra_periplos/article/view/27585

."Diáspora, refugiado e migrante: perspectiva etnográfica em mobilidade e transfronteiriça". Sociedade e Cultura, 20, 2017c. Disponível em: https://www.revistas.ufg.br/fchf/issue/view/1980/ show Toc

. Diáspora. In: NEIBURG, Federico (Org). Conversas etnográficas haitianas. Rio de Janeiro: Papéis Selvagens Edições, 2017d.

JOSEPH, Handerson e JOSEPH, Rose-Myrlie. 2015c. "As relações de gênero, de classe e de raça: mulheres migrantes haitianas na França e no Brasil". Revista de Estudos e Pesquisas sobre as Américas, 9 (2): 1-33. http://periodicos.unb.br/index.php/repam/article/view/17266 
